ORIGINAL ARTICLE

\title{
Prevention of work related skin problems: an intervention study in wet work employees
}

\author{
E Held, K Mygind, C Wolff, F Gyntelberg, T Agner
}

Occup Environ Med 2002;59:556-561

See end of article for authors' affiliations

....................

Correspondence to: Dr E Held, Department of Dermatology, Gentofte Hospital, University of Copenhagen, Niels

Andersensvej 65, 2900

Hellerup, Denmark;

elisabeth-held@dadlnet.dk

Accepted

13 February 2002

\begin{abstract}
Aims: To evaluate the effect of implementation of an evidence based skin care programme for wet work employees as part of an occupational health and safety management system.

Methods: 375 wet work employees were included in a prospective randomised controlled trial, allocated to either intervention ( $n=207)$ or control $(n=168)$. The intervention group was exposed to a skin care programme during the five month study period. The intervention included an educational programme for a group of frontline employees, who underwent formalised training, and subsequently introduced the information to their colleagues. As part of the intervention a skin care policy including written instructions was established at each workplace. Both groups answered a test quiz, completed questionnaires on behaviour and symptoms, and underwent clinical examination of their hands before and after the five month period.

Results: No difference between the intervention and the control group was found at baseline with respect to clinical symptoms or behaviour. Evaluation after the five months of intervention revealed a significantly higher information level on skin care in the intervention group compared to the control group, a significant change in behaviour in the intervention group but not in the control group, and significantly less skin symptoms as evaluated clinically in the intervention group but not in the control group. No significant difference was found for self reported skin problems.

Conclusions: The intervention was successful with respect to information level (knowledge), behaviour, and clinical symptoms. Implementation of a skin care programme as part of an occupational health and safety management system is recommended as a prophylactic measure for employees in wet occupations.
\end{abstract}

S kin diseases constitute up to $30 \%$ of all occupational diseases for which compensation is payable. ${ }^{1}$ The most common work related dermatosis is contact dermatitis; the annual incidence is reported to be 12.9 per 100000 workers. ${ }^{2}$ As occupational skin diseases are disabling, ${ }^{3}$ mostly affect young people, are expensive for society, ${ }^{4}$ and recently were reported to be an important predictor for long term unemployment, ${ }^{5}$ prevention is necessary. Occupational contact dermatitis (OCD) is most often localised to the hands, and employees in wet occupations are at increased risk of this disease. ${ }^{1}$ Epidemiological and clinical studies have identified risk factors for development of irritant skin reactions in wet occupations, and experimental studies have identified preventive measures that may reduce the risk of getting OCD. On the basis of these studies an evidence based skin care programme has been developed. Implementation of the skin care programme was by formation of participatory teams, ${ }^{67}$ and by using selected specifications from an occupational health and safety management system. ${ }^{8}$

The aim of the present study was to investigate the effect of implementation of a skin care programme in a wet work occupation as part of an occupational health and safety management system with respect to improvement of knowledge about skin care, change of behaviour, and reduction of irritant skin symptoms.

\section{METHODS}

\section{Population}

The study population was recruited among employees (nursing, kitchen, and cleaning) from seven old people's homes in the City of Copenhagen. Inclusion criteria were: being a permanent employee, having wet work, and a working week of at least 28 hours. Each of the seven workplaces was allocated by random to either the intervention group or the control group. A total of 375 employees were included in the study, 207 in the intervention group and 168 in the control group. Power analysis calculated that in order to detect $20 \%$ improvement (clinical evaluation) in the intervention group, a sample size of 210 participants equally divided between the two groups had to be included. ${ }^{9}$ All employees were informed about the project at information meetings. Participation in the study was voluntary, all participants gave informed written consent, and the local ethical committee approved the study.

\section{Random selection procedure}

All old people's homes located in the City of Copenhagen $(\mathrm{n}=110)$ were divided into three groups according to the number of employees $(<40,40-70$, and $>70)$. Subsequently three workplaces (one of each size) were randomly chosen for the intervention group and four for the control group (to get a fairly equal number of participants in the two groups). If an old people's home did not want to participate in the study, another was randomly chosen from the same group.

\section{Study design}

The intervention group (I) and the control group (C) were examined twice; at the start $\left(\mathrm{T}_{1}\right.$, October to November 1998) and at the end of the study, five months later $\left(\mathrm{T}_{2}\right.$, March to April 1999). The intervention group was exposed to a skin care programme during the study period.

\section{Intervention}

A formalised educational programme was given in each workplace to a team of frontline employees (10-20 persons) called the participatory team. This team included employees willing to undergo an educational programme and willing to teach and instruct other employees. The workplace did itself choose 
Table 1 Demographic profile (characteristics at baseline)

\begin{tabular}{llll}
\hline Characteristics & Intervention & Control & p value \\
\hline No. of employees & 207 & 168 & \\
Participation† & $83 \%$ & $76 \%$ & 0.144 \\
Women (n) & $193(93 \%)$ & $149(89 \%)$ & 0.144 \\
Drop outs (n) & $51(25 \%)$ & $37(22 \%)$ & 0.62 \\
Age (y) (mean and range) & $42.4(21-61)$ & $40.2(19-62)$ & $0.044^{*}$ \\
Average duration of employment (y) (median and quartiles) & $5(2-11)$ & $4(1-9)$ & 0.44 \\
Weekly work hours (no.) (median and quartiles) & $35(30-37)$ & $35(32-37)$ & 0.73 \\
Atopic dermatitisł (doctor diagnosed) (\%) & 10.7 & 6.0 & 0.14 \\
Rhinitis (\%) & 24.6 & 19.9 & 0.32 \\
Asthma (\%) & 10.7 & 10.3 & 1.00 \\
Ear piercing (\%) & 82.1 & 80.8 & 0.79 \\
Metal rash (\%) & 44.6 & 37.5 & 0.20 \\
Children <4 y (\%) & 9.3 & 18.5 & $0.010^{*}$ \\
Dishwashing machine (\%) & 32 & 25 & 0.17 \\
\hline *Indicates p<0.05. & & & \\
$\dagger$ Data indicate percentage of employees who actually participated out of the possible number of employees. \\
$\ddagger$ The question in the questionnaire was: "Has a doctor ever told you that you have atopic eczema (childhood \\
eczema, atopic dermatitis)?". \\
\end{tabular}

Table 2 Reasons for dropping out and not participating at $T_{2}$

\begin{tabular}{lll}
\hline & Intervention & Control \\
\hline Change of job during the intervention period $(\mathrm{n})$ & 19 & 11 \\
Sick leave, maternity leave, holiday, or course attendance $(\mathrm{n})$ & 16 & 15 \\
Did not want to participate in the follow up examination $(\mathrm{n})$ & 16 & 11 \\
Participants who were lost to follow up at $\mathrm{T}_{2}$ (total $\mathrm{n}$ ) & 51 & 37 \\
\hline
\end{tabular}

the members of the participatory team, but it was mandatory that the team included at least one person from management, one from the local safety board, and one from each working sector (nursing, kitchen, and cleaning).

The purpose of the educational programme (see Appendix) was to give the participants prerequisites to understand an evidence based skin care programme, to develop a skin care policy with written instructions referring to the skin care programme, and to train the participants in communicating the skin care policy to their colleagues. After training, the participatory team subsequently passed the information on to their colleagues. They could choose freely the way of communication; for example, by arranging information meetings, making posters, or giving individual instructions to each employee. Provision of written instructions was, however, mandatory. All instructions had to be approved by the local safety board before implementation.

In the evidence based skin care programme, current knowledge from epidemiological and experimental studies was used about proper glove use, correct hand wash, and use of hand disinfectants and moisturisers. The skin care programme is given in details elsewhere. ${ }^{10}$ Together with the educational programme, moisturisers (fragrance free and with full ingredient list but without the trade name) with documented efficacy, $^{11}$ and cotton gloves ${ }^{12}$ were freely available for all employees.

\section{Evaluation of knowledge}

At $\mathrm{T}_{2}$ all participants took part in a quiz testing basic knowledge about skin care. The quiz included seven questions concerning water temperature for hand washing, use of finger rings, use of disinfectants, use of protective gloves and cotton gloves, how to treat dry skin, and choice of moisturiser.

\section{Evaluation of behaviour and skin symptoms}

Examination of the intervention and the control group was performed at $\mathrm{T}_{1}$ and $\mathrm{T}_{2}$ by self administered questionnaires and clinical examinations. The questionnaire included baseline characteristics, results from which are reported in table 1, prior and present skin symptoms, and questions on behaviour. Afterwards a trained doctor or nurse examined their hands. In order to ensure that the doctor and the nurse were not biased in the clinical evaluation, a blinded dermatologist on the same day additionally examined a subset of the patients at $\mathrm{T}_{2}$. Clinical examination included registration of symptoms and localisation; results were transformed into a scoring system dividing the participants into five groups: no skin symptoms, very mild, mild, moderate, and severe.

\section{Statistics}

The statistical software package SPSS 10.0 was used. Non-parametric statistics were used for cross sectional analysis (comparison of independent groups: Mann-Whitney (continuous and ordinal data), and Pearson's $\chi^{2}$ test (Fisher's exact test in $2 \times 2$ tables) (categorical data)) and for analysis of change over time (paired data: McNemars (dichotomous data) and marginal homogeneity test (ordinal data)). ${ }^{13}$ A MannWhitney test was used to see whether the change in the intervention group was significantly different from the change in the control group $(\Delta \mathrm{I} v \Delta \mathrm{C})$. If this test was significant, a more causal interpretation on the effect of the intervention is feasible. Kappa analysis was used to test for interobserver agreement. ${ }^{13}$ Logistic binary regression analyses were used to identify risk factors/preventive measures for skin symptoms at baseline, for reduction of skin symptoms during the study, and for analysis of drop outs. All tests applied were two tailed, and a significance level of 0.05 was chosen.

\section{RESULTS}

A total of 207 and 168 employees were recruited to the intervention group and the control group, respectively $\left(\mathrm{T}_{1}\right) ; 75 \%$ (156/207) in the intervention group and 78\% (131/168) in the 

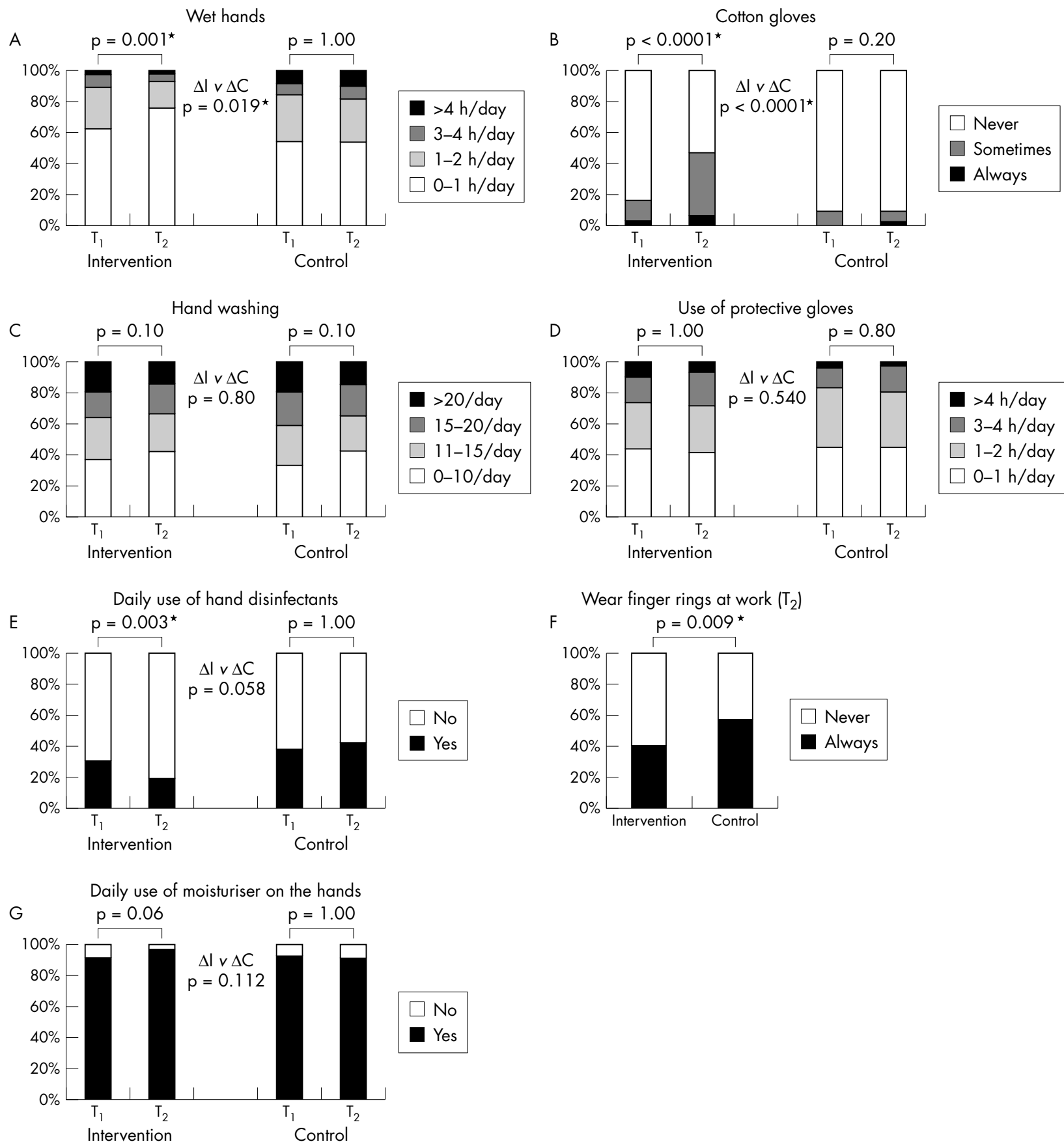

Figure 1 Daily behaviour with respect to wet work (hours), use of cotton gloves, frequency of hand washing, use of gloves, disinfectants, finger rings (only data from $\mathrm{T}_{2}$ are available), and moisturisers at $\mathrm{T}_{1}$ and $\mathrm{T}_{2}$ in the intervention group and in the control group. ${ }^{*}$ Indicates $p<0.05$.

control group fulfilled the study and participated at $\mathrm{T}_{2}$. Table 1 gives characteristics of the intervention group and the control group.

\section{Drop outs}

A total of 25\% (51/207) in the intervention group and 22\% (37/ 168 ) in the control group dropped out and did not participate at $\mathrm{T}_{2}$. Table 2 gives reasons for dropping out. When comparing drop outs with participants who completed the five month period, no significant differences were found with respect to basal characteristics (see table 1 ), wet work behaviour at $\mathrm{T}_{1}$, or occurrence of skin symptoms (self reported and clinical examination) at $\mathrm{T}_{1}$ in a binary logistic regression analysis.

\section{Knowledge}

The intervention group had a significantly higher score in the quiz (mean rank: 156) compared to the control group (mean rank: 128$)(p=0.003) ; 65 \%(100 / 155)$ in the intervention group compared to $49 \%(65 / 127)$ in the control group had more than five correct answers in the quiz $(\mathrm{p}=0.029)$. Median values and 25/75 percentiles were $6(5 / 7)$ correct answers in the intervention group and 5 (4/7) correct answers in the control group.

\section{Behaviour}

Figure 1 presents data on behaviour with respect to wet work (hours), use of gloves, moisturisers, disinfectants, and finger 
Table 3 Clinical examination of a subset of participants $(n=67)$ by the nurse/doctor as well as by a blinded dermatologist $\left(\mathrm{T}_{2}\right)$

\begin{tabular}{llllll}
\hline \multirow{2}{*}{ Grading } & \multicolumn{2}{l}{ Doctor/nurse } & & \multicolumn{2}{l}{ Dermatologist } \\
\cline { 2 - 3 } \cline { 5 - 6 } & Intervention & Control & & Intervention & Control \\
\hline None/very mild & 23 & 22 & 23 & 25 \\
Mild/moderate/severe & 4 & 18 & 4 & $p=0.055$ \\
Intervention $v$ control & & $p=0.016^{*}$ & & $p$ \\
\hline *Indicates $p<0.05$ & & & & & \\
\hline
\end{tabular}

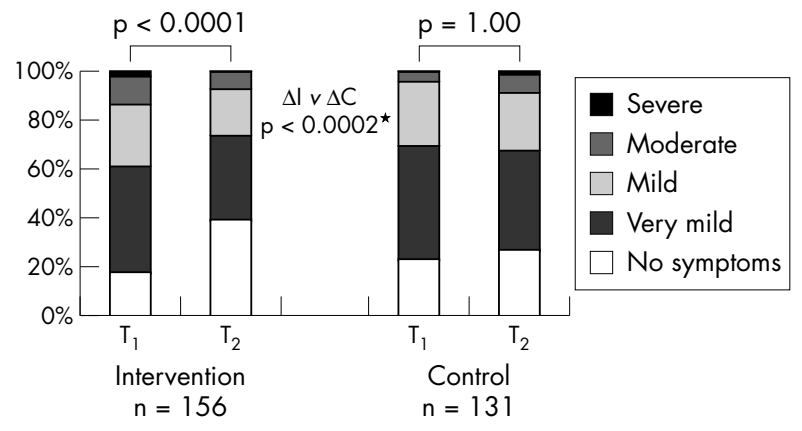

Figure 2 Results from the clinical examination. *Indicates $p<0.05$.

rings at $\mathrm{T}_{1}$ and $\mathrm{T}_{2}$. No difference between the intervention and the control group was found at $\mathrm{T}_{1}$ with respect to behaviour. The number of wet work hours was significantly reduced $(38 \%$ had wet hands for more than one hour a day at $\mathrm{T}_{1}$ compared to $24 \%$ at $\mathrm{T}_{2}, \mathrm{p}<0.001$ ), and the use of cotton gloves was significantly increased in the intervention group from $T_{1}$ to $T_{2}(16 \%$ used cotton gloves at $\mathrm{T}_{1}$ compared to $47 \%$ at $\mathrm{T}_{2}, \mathrm{p}<0.0001$ ), while no change was observed in the control group (fig $1 \mathrm{~A}, \mathrm{~B}$ ). Furthermore, this change in the intervention group was significantly different from the change in the control group $(\Delta \mathrm{I} v \Delta \mathrm{C}, \mathrm{p}<0.019$ and $\mathrm{p}<0.0001$ respectively). The number of hand washes and time wearing protective gloves as well as the use of moisturisers remained unchanged throughout the study period (fig $1 \mathrm{C}, \mathrm{D}, \mathrm{G}$ ). The use of disinfectants was reduced in the intervention group $(30 \%$ used hand disinfectants at $\mathrm{T}_{1}$ compared to $19 \%$ at $\mathrm{T}_{2}, \mathrm{p}<0.003$ ) but not in the control group (fig 1E). Significantly less participants wore daily finger rings in the intervention group compared to the control group at $\mathrm{T}_{2}(61 \%$ never used finger rings at work in the intervention group compared to $44 \%$ in the control group, $\mathrm{p}<0.009$; fig $1 \mathrm{~F})$.

\section{Skin symptoms}

\section{Self reported skin problems}

Participants having two or more of the following symptoms: redness, vesicles, papules, itching, scaling, dryness, fissuring, rough and thickened, or suppurate skin changes lately or at present were registered as having skin problems. At $\mathrm{T}_{1} 25 \%$ in the intervention and $30 \%$ in the control group had current skin problems on their hands $(p=0.32)$; figures for $T_{2}$ were $27 \%$ in the intervention group and $34 \%$ in the control group $(p=0.40)$.

\section{Clinical examination}

Figure 2 gives results from the clinical examination. No difference between the intervention and the control group was found at $T_{1}$ with respect to clinical skin symptoms. After the intervention less skin symptoms were found in the intervention group $(p<0.0001)$ but not in the control group $(p=1.00)$. Furthermore, the change in clinical skin symptoms during the study period was significantly different between the intervention and the control group ( $\Delta \mathrm{I} v \Delta \mathrm{C}$, $p<0.0002)$. A subsample of participants $(n=67)$ was examined twice at $\mathrm{T}_{2}$ by the doctor or the nurse as well as by the blinded dermatologist (table 3 ). When testing for interobserver agreement between the doctor/nurse and the dermatologist, a kappa value of 0.68 was found.

\section{Regression analysis}

Two regression analyses were performed in order to assess possible risk factors/preventive measures for (1) baseline level of skin symptoms and (2) change in skin symptoms in the intervention group from $\mathrm{T}_{1}$ to $\mathrm{T}_{2}$. The dependent variables were in both cases derived from the ordinal scale used for clinical evaluation of skin symptoms and were transformed to a dichotomous scale to be able to perform binary logistic regression. The baseline level of skin symptoms was measured as "none/very mild" versus "mild/moderate/severe". The change in skin symptoms was measured as "improved" versus "unchanged/not improved". Potential predictors were relevant demographic data, data on behaviour, and results from the clinical examination. To avoid too many independent variables in the regression model, the potential predictors were initially screened in a bivariate analysis for partial association to the dependent variables. A significance level of 0.15 was used here to include the predictors into to the logistic regression. However, the variables "age", "children $<4$ years", and "group membership (I $v \mathrm{C})$ " "were included regardless of the outcome of the screening. The selection of significant predictors followed a forward stepwise procedure. After the selection, the models were re-estimated by entering all significant variables en bloc. In the first model risk factors identified as significant for having skin symptoms of "mild/moderate/severe" degree at baseline were indicator variables for "previous or present atopic dermatitis" (OR $=2.18$; CI: 1.04 to $4.56 ; \mathrm{p}=0.038)$ and "history of metal rash" (OR $=1.63$; CI: 1.05 to $2.5 ; \mathrm{p}=0.029)$. In the second model, no significant predictors for the change in skin symptoms were found.

\section{How the intervention was implemented}

The following data are from $\mathrm{T}_{2}$ showing how the intervention was implemented in the intervention group: $90 \%$ of the participants agreed that they had received information about good skin care during the five month of intervention; $97 \%$ of the employees had received moisturisers that were freely provided; $79 \%$ had received cotton gloves; and $59 \%$ of the participants stated they had either a huge or almost huge benefit from the educational programme.

\section{DISCUSSION}

Results of the present study show that an educational programme directed at participatory teams may be a successful preventive measure at workplaces with wet work. Information level about skin care was significantly improved in the intervention group and risk behaviour was minimised in important domains: number of hours with wet hands was reduced and use of cotton gloves increased. Furthermore, a statistically significantly reduced number and severity of irritant skin symptoms on the hands was found in the intervention group compared to the control group. 
Recently the use of participatory programmes, which means that employees and management cooperatively identify safety and health problems and implement appropriate changes in work practices, has been tested successfully in healthcare employees. ${ }^{67}$

In the present study the intervention included formation of participatory teams, which implies education of a group of frontline employees and members of management who subsequently communicate the information to their colleagues. This ensures that the recommendations in the evidence based skin care programme are passed on to all employees in a form that is understood and accepted. Furthermore, the intervention used selected parts of an occupational health and safety system, including a development of a skin care policy authorised by the top management of the organisation. ${ }^{8}$ This ensures that the system is integrated in all levels of the organisational structure at the workplace and that the management is committed to support and enforce the policy. ${ }^{15}$ The intervention is aimed at the workplace and not at the individual subject, which means that the motivation of the individual is less important, as the policy for the workplace as such is influenced. A recent postal questionnaire survey of 1100 UK companies revealed that only $27 \%$ had a skin care policy. ${ }^{16}$

The recommendations in the skin care programme were based on scientific results from experimental and epidemiological studies, and were as such documented to be effective beforehand. Moisturisers and cotton gloves were provided for the working places during the intervention period to make sure that the intervention was not blocked by practical problems. The success of the intervention in the present study may be related to the fact that the behavioural changes were limited to small practical changes during work hours (for example, use of cotton gloves, wash hands instead of using hand disinfectants). Furthermore, positive changes in skin symptoms caused by altered behaviour can be followed closely and motivate the employees to continue the skin care programme. Contact dermatitis is an intermittent disease showing great intraindividual variation over time and with seasons. This is probably the reason why we could not find any significant variables associated with improvement of skin symptoms in the intervention group.

In the present study focus was on registration of skin symptoms/problems, and not on identification of hand eczema cases. Dry or chapped skin on the hands grades imperceptively into irritant contact dermatitis, ${ }^{17}$ and the line dividing non-eczema from eczema may be hard to define and unrealistic in the real life situation. In the multivariate analysis atopic dermatitis was identified as a significant risk factor for skin symptoms, which confirms observations from numerous other studies. ${ }^{31819}$ Presence of nickel allergy is generally accepted as a risk factor for development of hand eczema. ${ }^{20}$ In the present study metal rash was a significant risk factor for having skin symptoms at baseline. Metal rash is strongly associated with nickel allergy, but may also include skin irritation.

In contradiction to the clinical examination, a slightly increased number of participants in both the intervention group and the control group had self reported skin problems after the intervention. Participation in the study introduced information bias in both the intervention and to a lesser degree in the control group, making the participants focus more on skin problems.

Both the doctor/nurse and the blinded dermatologist found that after intervention the intervention group had less skin symptoms than the control group. Furthermore, a kappa value of 0.68 was found, indicating good agreement. ${ }^{13}$ The same kind of interobserver evaluation was used in another study on hand eczema. ${ }^{21}$

This is the first reported intervention study including a control group aiming at reduction of irritant skin symptoms.

\section{Main messages}

- Irritant skin reactions are common in wet work employees

- Staff training improved knowledge about wet work procedures, had a positive effect on wet work behaviour, and resulted in less skin symptoms as evaluated clinically.

- Intervention in wet work employees, including a skin care programme, had an overall positive effect.

\section{Policy implications}

- Intervention at the workplace should include both employees and management.

- Implementation of a skin care programme at the workplace should focus on frontline employees and formation of participatory teams.

- Intervention studies are necessary to prove effectiveness of preventive measures.

Although long term observations are necessary to confirm the positive effect of intervention, the present results are promising. In future studies, economic cost-benefit analysis should be included.

\section{ACKNOWLEDGEMENTS}

The study was funded by The Danish Working Environment Council and Aage Bangs Fund. Statistical support was provided by UNI-C, Copenhagen.

\section{APPENDIX: EDUCATIONAL PROGRAMME \\ Teaching team}

- A nurse from the local department of occupational health and a consultant from the employees' health service. Both teachers were well educated and experienced.

\section{Methods}

- $2 \times 4 \mathrm{~h}$ course, 14 days in between

- Informational video on hand eczema

- Booklet on preventive measures

- Diary (self registering of daily behaviour)

- Interactive dialogue

- Role play

- Preparation of written instructions

- Overheads (text, drawings, and photos)

\section{Programme topics}

- Anatomy and physiology of normal and diseased skin

- What is eczema and what are the symptoms

- Acute and chronic eczema

- Allergic and irritant eczema

\section{Practical instructions}

- Hand washing

- Moisturisers

- Protective gloves

- Cotton gloves

Reinforcement

- Meeting with instructors after 6 weeks

\section{Authors' affiliations}

E Held, T Agner, Department of Dermatology, Gentofte Hospital, University of Copenhagen, Denmark

K Mygind, Occupational Health Service, Health Administration, City of Copenhagen, Denmark

C Wolff, F Gyntelberg, Clinic of Occupational and Environmental

Medicine, Bispebjerg Hospital, University of Copenhagen, Denmark

\section{REFERENCES}

1 Diepgen TL, Coenraads PJ. The epidemiology of contact dermatitis. Int Arch Occup Environ Health 1999;72:496-6. 
2 Cherry N, Meyer JD, Adisesh A, et al. Surveillance of occupational skin disease: EPIDERM and OPRA. Br J Dermatol 2000;142:1 128-34.

3 Meding B. Epidemiology of hand eczema in an industrialized city. Acto Derm Venereol 1990;153(suppl): 1-43.

4 Halkier-Sorensen L. Occupational skin diseases. Contact Dermatitis 1996;3(suppl): 1-12.

5 Leino-Arjas P, Liira J, Mutanen P, et al. Predictors and consequences of unemployment among construction workers: prospective cohort study. BM 1999:4:600-5.

6 Evanoff BA, Bohr PC, Wolf LD. Effects of a participatory ergonomics team among hospital orderlies. Am J Ind Med 1999;35:358-65.

7 Bohr PC, Evanoff BA, Wolf LD. Implementing participatory ergonomics teams among health care workers. Am J Ind Med 1997;32:190-6.

$8 \mathrm{BSI}$. Occupational health and safety management systemsspecifications. Occupational health and safety assessment series OHSAS 18001. London: British Standards Institution, 1999.

9 Dean AF, Dean JA, Burton AH, et al. Epi Info version 6: a word processing, data base, and statistics program for epidemiology on microcomputers. Atlanta: Centers for Disease Control.

10 Held E, Wolff C, Gyntelberg F, et al. Prevention of work-related skin problems in student auxiliary nurses. An intervention study. Contact Dermatitis 2001;44:297-303.

11 Ramsing DW, Agner T. Preventive and therapeutic effects of a moisturizer. An experiment study on human skin. Acta Derm Venereol 1997;77:335-7.
12 Ramsing DW, Agner T. Effect of glove occlusion on human skin (II). Long-term experimental exposure. Contact Dermatitis 1996;34:258-62. 13 Altman DG. Practical statistics for medical research. London: Chapman \& Hall, 1991.

14 Kuritz SJ, Landis JR, Koch GG. A general overview of Mantel-Haenszel methods: application and recent developments. Annu Rev Public Health 1988; 9: 123-60.

15 Ford JK, Fisher S. The transfer of safety training in work organizations: a systems perspective to continuous learning. Occup Med 1994;9:241-59

16 Douglas E, Rushton L, Williams HC. Is occupational dermatitis being taken seriously by UK industries? Occup Med 1999;49:85-91.

17 Wilkinson DS. Hand eczema, 2nd edn. Boca Raton, FL: CRC Press, 2000.

18 Nilsson E, Mikaelsson B, Andersson S. Atopy, occupation and domestic work as risk factors for hand eczema in hospital workers. Contact Dermatitis 1985; 143:216-23.

19 Rystedt I. Hand eczema and long-term prognosis in atopic dermatitis (thesis). Acta Derm Venereol 1985;117(suppl): 1-59.

20 Menne T, Borgan O, Green A. Nickel allergy and hand dermatitis in a stratified sample of the Danish female population: an epidemiological study including a statistic appendix. Acta Derm Venereol 1982;62:35-41.

21 Yngveson M, Svensson A, Isacsson A. Evaluation of a self-reported questionnaire on hand dermatosis in secondary school children. Acta Derm Venereol 1997;77:455-7.

\section{$\mathrm{ECHO}$}

Sputum cell profile: no help in occupational asthma

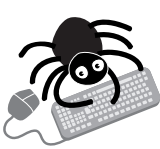

Please visit the Occupational and

Environmental Medicine website [www occenvmed.com for link to this full article. nalysing the type of inflammatory cells in sputum does not help to confirm a diagnosis of occupa-

tional asthma in workers with borderline features of the condition. Asthma related to low molecuLlar weight agents fell into eosinophilic and non-eosinophilic types but did not correlate with peak expiratory flow (PEF) response to exposure at work.

Examination of induced sputum from 38 consecutive workers with asthma related to low molecular weight agents showed that only 14 had sputum eosinophilia (eosinophils $>2.2 \%$ of non-squamous cells). Grouping the workers according to whether they had sputum eosinophilia or not revealed that neutrophils were present in similar proportions in each group (mean (SD) 59.5 (19.6)\% v 55.1 (18.8)\%, respectively). Furthermore, no differences were apparent in diurnal variation in PEF and drop in PEF during work periods between the two groups. Other respiratory measures indicated that sputum eosinophilia correlated with more severe asthma and greater bronchodilator reversibility.

The researchers hypothesised that in asthma related to low molecular weight agents workers with small but consistent falls in PEF and whose diurnal variation in PEF was within normal values would have a neutrophilic, not an eosinophilic, inflammatory airway response and this could be used to corroborate the diagnosis. Such physiological behaviour in PEF by itself makes it difficult to decide whether to diagnose occupational asthma or not.

A Thorax 2002;57:231-236. 